\title{
A PSICOPEDAGOGIA MODULAR: Uma nova perspectiva no campo da avaliação
}

\author{
Modular psychopedagogy: A new perspective in the evaluation field
}

\author{
Elizabeth Carvalho da Veiga
}

Doutora em Psicologia Cognitiva, professora da Graduação e Pós-Graduação da Pontifícia Universidade Católica do Paraná (PUCPR), Curitiba, PR - Brasil, e-mail: bethveiga@hotmail.com

\section{Resumo}

Este artigo apresenta uma reflexão sobre a avaliação da psicopedagogia modular, proposta que conflui perspectivas teóricas e metodológicas procedentes de três teorias: a Teoria Triárquica de Sternberg, Teoria das Inteligências Múltiplas de Gardner, que integram muito bem os dados disponíveis no campo da modularidade da mente, e a Teoria da Epistemologia Convergente de Visca. Esta proposta apresenta uma estrutura teórica e um modelo dinâmico de avaliação, entendido como um processo interativo, flexível e individualizado em que o profissional interpõe-se entre o sujeito e a tarefa, modificando-a (ajustando a ordem, a complexidade, o tempo...) para que o sujeito diante do obstáculo possa superá-lo e mostrar seu verdadeiro potencial.

Palavras-chave: Psicopedagogia. Modularidade. Aprendizagem. Inteligência.

\begin{abstract}
This article presents a reflection about the modular psychopedagogy evaluation, which joins the methodological and theoretical perspectives that come from three theories: the Triarchic Theory of Sternberg, the Multiple Intelligences Theory of Gardner, that integrates the available information in the mind modularity fields, and the Convergent Epistemology Theory of Visca. This proposal presents a theoretical structure and a dynamic evaluation model, understood as an interactive process, flexible and individualized where the professional is positioned between the individual and the task, changing it (adjusting the order, the complexity, the time...) so that the individual, once against the obstacle, can get it over and show his/her real potential.
\end{abstract}

Keywords: Psychopedagogy. Modularity. Learning. Intelligence. 


\section{INTRODUÇÃO}

Há duas décadas a práxis psicopedagógica no Brasil foi enriquecida com a teoria da Epistemologia Convergente de Jorge Visca (1987, 1991), que conflui perspectivas teóricas e metodológicas procedentes de três teorias: Epistemologia Genética, de Jean Piaget, Teoria Psicanalítica, na qual se destacam Freud e Melaine Klein, e a Teoria Social de Pichon Riviére.

A partir das pesquisas no campo da neurociência, novas descobertas a respeito do cérebro passam a ser incorporadas nos estudos que envolvem a mente humana. Para a neuropsicologia, todos os processos mentais de caráter cognitivo ou afetivo, conscientes ou inconscientes, são propriedades emergentes de processos cerebrais e realizam-se em sistemas, redes, módulos cerebrais dentro de um organismo em um determinado meio. No caso do homem, para que se desenvolvam os processos mentais de caráter superior é necessário um meio sociocultural, segundo Vigotsky (1979, 1989).

O cérebro recebe e processa grande quantidade de informação mediante sistemas distintos, porém ainda não se conhece a totalidade das regiões funcionais do cérebro. O que distingue o cérebro humano dos demais é a variedade de atividades especializadas que é capaz de aprender, bem como a maneira de repartir as funções entre os dois hemisférios. O movimento da neuropsicologia na psicopedagogia é relativamente recente. Caminhar por meio das bases filogenéticas, ontogenéticas e neuropsicológicas é o grande desafio.

A psicopedagogia no Brasil tem uma tradição e uma herança de muitos anos, aplicando seus conceitos para diagnosticar dificuldades de aprendizagem. Baseia-se em conhecimentos de diversas áreas. Neste momento histórico, desde a década de 90 o cérebro vem sendo foco das grandes descobertas e o papel da neurociência torna-se fundamental na compreensão da cognição humana. $\mathrm{Na}$ virada do milênio, em princípios do século XXI, não se pode deixar de fora as contribuições advindas da Teoria Modular da Mente.

Com o aprofundamento nos estudos do cérebro, propõe-se uma nova visão à psicopedagogia, sistematizando os novos conhecimentos e propostas provenientes das pesquisas e descobertas a respeito do cérebro e seu funcionamento, no sentido de repensar a psicopedagogia sob a perspectiva da
Teoria Modular a Mente. A psicodegagogia modular (Veiga \& Garcia, 2005, 2006) está voltada para a potencialização de todos os sistemas inteligentes do indivíduo, "descentralizando" o olhar do fracasso e focando em seu sucesso.

\section{Psicopedagogia modular}

A psicopedagogia, na perspectiva da Teoria Modular da Mente, considera os processos mentais e as habilidades envolvidas em cada inteligência do modelo triárquico de Sternberg, relacionando-os com cada sistema inteligente proposto por Gardner. A teoria da Psicopedagogia Modular integra perspectivas teóricas e metodológicas de três teorias: Teoria Triarquica da mente (Sternberg, 1983, 1990, 1997), Teoria das Inteligências Múltiplas (Gardner, 1988, 1992, 1995, 1997) e a Epistemologia Convergente (Visca, 1987). Essa proposta implica mudanças na organização teórico-prática da psicopedagogia. Revela como os processos mentais de cada inteligência estão atuando a partir do funcionamento das habilidades cognitivas correspondentes a cada processo mental, que por sua vez corresponde a uma determinada inteligência, propiciando o conhecimento das capacidades e dificuldades em cada sistema inteligente.

$\mathrm{O}$ modelo da psicopedagogia modular permite transitar pelos sistemas inteligentes do indivíduo, avaliando e intervindo de maneira a maximizar as capacidades do sujeito, desenvolver estratégias que favoreçam sua aprendizagem, auxiliando-o a sair do campo da memorização e reprodução das informações. Com essa nova perspectiva no campo psicopedagógico, resgata-se o perfil cognitivo e acerca-se da zona de desenvolvimento proximal nos sistemas inteligentes. Essa proposta transforma o psicopedagogo em um investigador em ação, avaliando e intervindo simultaneamente.

Esse modelo parte de uma concepção dinâmica e pluralista dos sistemas inteligentes. Não considera a concepção de estrutura geral cognitiva, estática ou até mesmo imutável que assume o quociente intelectual (QI) como medida classificatória da inteligência e as estruturas de pensamento de forma generalizada, o que acaba por contribuir muito pouco na avaliação psicopedagógica. A psicopedagogia modular não se limita ao uso de testes formais e tampouco 
prognostica o futuro do sujeito com base em informações muitas vezes fixas e situacionais.

Esse modelo defende a ideia de avaliar e intervir simultaneamente, pois a avaliação é compreendida como uma ação de cooperação entre o psicopedagogo e o sujeito, retirando o profissional da posição de observador, medidor e registrador de respostas. O psicopedagogo passa a reconhecer como funcionam os sistemas inteligentes, seus processos mentais e habilidades cognitivas, aproximando-se da arquitetura cognitiva, do perfil cognitivo do sujeito.

Com a psicopedagogia modular, procurase compreender o funcionamento do perfil cognitivo do sujeito, o que facilita muito a criação de um programa de intervenção, pois esse deve estar voltado à potencialização de todos os sistemas inteligentes, seus processos e habilidades, consolidando os aspectos motivacionais e a autoestima do sujeito, fatores determinantes no seu desempenho cognitivo.

A avaliação utilizada nessa proposta é dinâmica e vem reestruturar o papel do psicopedagogo nesse processo, passando a ser alguém que interage em situação de aprendizagem, pondo em cena estratégias de mediação e não de pura testagem e medição. $\mathrm{Na}$ avaliação dinâmica, o profissional deve ir além dos resultados apresentados - deve tentar modificar o estado atual do sujeito. Durante a mediação nesse processo, novos procedimentos e habilidades cognitivos podem emergir.

Segundo Fonseca $(2007,1999)$, dentro dessa ótica, devem ser preocupação num processo de avaliação os pontos fortes e o nível ótimo de desempenho que o sujeito é capaz de produzir. O autor afirma ainda que a avaliação deve fornecer informações relevantes para a aprendizagem, portanto, precisa ser dinâmica e prospectiva. Ele defende a ideia de que se deve alargar o repertório dos instrumentos de avaliação e não reduzi-lo, pois todas as contribuições são importantes quando se fala das complexas exigências da aprendizagem, em especial quando o público alvo se caracteriza por apresentar dificuldades nesse sentido. $\mathrm{O}$ autor propõe como objetivo principal de diagnóstico o que o sujeito é capaz de fazer quando mediado, e não a classificação ou tabulação do que aprendeu, evitando utilização de procedimentos classificatórios.

Dentro desse prisma de classificar o sujeito, Haywood (1992) já afirmava que os testes psicométricos tradicionais falham no processo de diagnóstico porque não apontam soluções para as dificuldades. Seguindo essa linha de raciocínio, pode-se citar Vygotsky $(1969,1962)$, que define a Zona de Desenvolvimento Atual (ZDA) como aquilo que o sujeito pode fazer no momento atual. A avaliação tradicional enfatiza a ZDA e a avaliação dinâmica atinge a Zona de Desenvolvimento Proximal (ZDP), ou seja, o que o sujeito pode fazer com o auxilio do outro (no processo de avaliação, o psicopegagogo).

A avaliação dinâmica, proposta utilizada pela psicopedagogia modular, busca descobrir os verdadeiros potenciais do sujeito para que esses possam favorecer a potencialização dos sistemas inteligentes. Segundo Spitz (1986) e Sharron (1987), a avaliação dinâmica é uma alternativa à avaliação tradicional, oferecendo dados significativos para os futuros encaminhamentos no processo de intervenção. Por meio da mediação levanta-se o potencial prospectivo do sujeito, e não apenas os seus obstáculos. Trata-se de avaliar como e quais processos mentais e habilidades cognitivas estão a favor da aprendizagem, caracterizando o funcionamento dos sistemas inteligentes.

Considerando a singularidade do processo de aprendizagem, a partir das contribuições da Teoria Modular, efetivamente se pode responder muitas inquietudes surgidas na prática psicopedagógica. Por meio da avaliação proposta na psicopedagogia modular é possível identificar processos e habilidades cognitivas envolvidas em cada inteligência e o quanto essas estão comprometendo a aprendizagem, favorecendo a continuidade de uma formação sólida e consistente na vinculação entre a teoria e prática psicopedagógica.

E necessário criar propostas que venham de encontro ao movimento científico que está acontecendo em torno da inteligência humana.

Os pesquisadores que compartilham da reforma científica das concepções de inteligência propõem definições menos restritas, enfatizando a natureza multifacetada da inteligência humana. Os teóricos defendem o aspecto qualificativo em sua concepção, para enfatizar a oposição à unicidade conceitual.

As medidas tradicionais correm o risco de enfatizar apenas dois sistemas inteligentes (linguístico e lógico-matemático) que compõem a inteligência acadêmica, centrando-se especificamente nas dificuldades acadêmicas de aprendizagem e não traduzindo efetivamente os sistemas 
inteligentes que nos instrumentalizam para aprender.

A avaliação modular é uma proposta que vem redimensionar os esforços no campo da avaliação e tem por objetivo tornar conhecido o perfil cognitivo do sujeito, com suas capacidades e limitações, de que modo as utiliza, e de que competências o sujeito está fazendo uso para aprender.

De acordo com Veiga e Garcia (2006), essa avaliação oferece um olhar além das potencialidades manifestas e propõe reconhecer outras que não sejam familiares ao aluno, identificando as diversas inteligências, competências ou habilidades e não apenas a linguística e lógica - matemática, de acordo com Gardner (1992), ou a inteligência analítica, de acordo com Sternberg (1983).

Tradicionalmente, a avaliação tem proporcionado informações sobre os mecanismos intrapsiquicos que são responsáveis pelas dificuldades na aprendizagem da criança, reduzindoa ao sistema linguístico e lógico-matemático. A proposta de avaliação da psicopedagogia modular, denominada de agora em diante como avaliação modular, enfatiza os processos cognitivos que compõem os sistemas inteligentes e não apenas os implicados nas dificuldades de aprendizagem.

Tanto os instrumentos formais como os informais são importantes. O profissional saberá mais sobre o sistema cognitivo do sujeito do que é normalmente registrado nas medidas formais. O uso de instrumentos informais dá ao indivíduo a oportunidade para mostrar sua aprendizagem por meio de várias modalidades. O capacita avaliar seus pontos fortes e fracos, articular o que aprendeu e aplicar as estratégias adequadas de pensamento nos diferentes sistemas inteligentes que favoreçam sua aprendizagem. Esse papel ativo no seu processo de avaliação torna-se menos ameaçador e o sujeito assume seu devido lugar, que é o de parceiro nesse processo.

A avaliação modular procurar imergir o sujeito durante um período em um ambiente enriquecido de recursos centrados nas oito inteligências e avaliar seu desempenho, integrando as inteligências de Gardner e as de Sternberg, para conhecer suas verdadeiras potencialidades numa abordagem mais holística.

$\mathrm{O}$ que nos diferencia de outros animais é a capacidade para refletir sobre a nossa maneira de pensar. A avaliação modular é fundamentada no processo metacognitivo, que literalmente significa "pensar sobre o próprio pensamento".

De acordo com García García (1994), o modelo de sistema mental que o autor propõe, a metacognição apresenta dois aspectos: conhecimento e controle. A metacognição como conhecimento considera três tipos de variáveis: pessoa, refere-se aos conhecimentos, capacidades, limitações, motivações, sentimentos, atitudes que uma pessoa tem de si mesma. Essa variável propicia um insight sobre suas características que podem facilitar ou não sua aprendizagem.

Outra variável tarefa/estratégia referese às características da tarefa, tipo de estratégias, adequação das mesmas e o que é apropriado para enfrentá-las. Essa variável auxilia o sujeito a realizar escolhas para o aprimoramento do seu modo de pensar.

A terceira variável é o contexto, refere-se às características e demandas do contexto, suas exigências e suas possibilidades, conhecimento social e juízo crítico nas distintas situações. Esta variável beneficia o sujeito no que se refere à visão geral do que se espera dele.

A consciência metacognitiva ajuda o sujeito a organizar sua aprendizagem. Através do processo metacognitivo-conhecimento, o sujeito pode compreender e melhorar a estrutura e funcionamento do seu sistema mental, modificando atitudes, motivações, interesses e sentimentos que afetam seu pensamento. Mediante esse processo de avaliação o sujeito poderá reconhecer e controlar os processos de pensamento e estratégias, analisando as possibilidades e limitações, com o objetivo de melhorar sua capacidade de pensar. A avaliação modular está centrada nas questões metacognitivas e no desempenho concreto das tarefas, não em resultados quantitativos.

\section{CONSIDERAÇÕES FINAIS}

É fundamental que se amplie a compreensão do que se está avaliando, lembrando que o que se está medindo são formas de experiências em desenvolvimento, que podem ser no contexto escolar ou de vida prática. Caso contrário, pode-se condenar o futuro de muitas pessoas ou supervalorizar outras, pois a experiência em desenvolvimento em uma área não garante o 
desenvolvimento em outra, apesar das possibilidades de transferência em função da relação existente entre as áreas.

A avaliação modular tem como objetivo intervir e mudar. Com isso, o profissional poderá potencializar os aspectos cognitivos já desenvolvidos e os que ainda se apresentam subdesenvolvidos das inteligências humanas no contexto escolar e extraescolar.

A psicopedagiogia modular deixa de apenas refletir as dificuldades e passa a mostrar todo o sistema cognitivo (facilidades e dificuldades). Essa forma de avaliação como um processo dinâmico leva o sujeito a beneficiar-se ao aprender por diferentes caminhos. Ao fim de todo o processo avaliativo tem-se um indivíduo já modificado em seus sistemas inteligentes.

\section{REFERÊNCIAS}

FONSECA, V. (2007). Cognição, neuropsicologia e aprendizagem: Abordagem neuropsicológica e psicopedagogica. Rio de Janeiro: Vozes.

FONSECA, V. (1999). Insucesso escola: Abordagem psicopedagógica das dificuldades de aprendizagem. Lisboa: Ancora.

HAYWOOD, H. C., BROOKS, P., \& BURNS, S. (1992). Bright star: Cognitive curriculum for young children. Massachusetts: Charlsbridge.

GARCÍA GARCÍA, E. (1994). Enseñar y aprender a pensar. Madrid: La Torre.

GARDNER, H. (1988). La nueva ciencia de la mente. Barcelona: Paidós.

GARDNER, H. (1992). Estructuras de la mente. México: FCE.

GARDNER, H. (1995). Inteligencias múltiples: La teoría en la práctica. Barcelona: Paidós.

GARDNER, H. (1997). La mente no escolarizada. Barcelona: Paidós.

SHARRON, H. (1987). Changing children's minds: Feuerstein's revolution in the teaching of intelligence. London: Souvenir.

SPITZ, H. (1986). The raising of intelligence. Hillsdale: LEA.
STERNBERG, R. J. (1983). Components of human intelligence. Cognition, 15, 1-4.

STERNBERG, J. R. (1990). Mas alla del cociente inteligente. Bilbao: Biblioteca de Psicología.

STERNBERG, J. R. (1997). Inteligencia exitosa. Barcelona: Paidós.

VEIGA, E. C., \& GARCIA, E. G. (2005). A psicopedagogia e a teoria modular da mente. Educación, Desarrollo y Diversidad, 8(1), 55-72.

VEIGA, E. C., \& GARCIA, E. G. (2006). A psicopedagogia e a teoria modular da mente. São José dos Campos: Pulso.

VISCA, J. (1987). Clínica psicopedagógica e epistemologia convergente. Porto Alegre: Artes Médicas.

VISCA, J. (1991). Psicopedagogia: Novas contribuições. Rio de Janeiro: Nova Fronteira.

VYGOTSKY, L. (1962). Thought and language. Cambridge: MIT.

VYGOTSKY, L. (1969). Do ato ao pensamento. Lisboa: Portugália.

VYGOTSKI, L. (1979). E1 desarrollo de los procesos psicológicos superiores. Barcelona: Crítica.

VYGOTSKI, L. (1989). Pensamento e linguagem. São Paulo: Martins Fontes.

Recebido: 23/03/2009

Received: 03/23/2009

Aprovado: 04/05/2009

Approved: 05/04/2009 